\title{
EFFECT OF MUSHROOM POWDER IN FRESH PASTA DEVELOPMENT
}

\author{
Paula Maria dos Reis Correia ${ }^{*}$, Sabrina Almeida Esteves ${ }^{2}$, Raquel Pinho Ferreira Guiné ${ }^{1}$ \\ I* CI\&DET Research Centre and Food Industry Department, Polytechnic Institute of Viseu, Viseu, Portugal, \\ e-mail: paulacorreia@esav.ipv.pt \\ ${ }^{2}$ Department of Food Industry, Agrarian School, Polytechnic Institute of Viseu, Viseu, Portugal
}

\begin{abstract}
Fresh pastas with Shiitake mushroom flour (MF) were produced. The MF was produced by drying the mushrooms at $40{ }^{\circ} \mathrm{C}$. Proportions of 5\%,10\%, and 15\% MF were used to prepare the fresh pastas (FP), with two types of wheat flour (regular (RWF) and $30 \%$ semolina wheat flour (SWF)). Mushroom pastas were analysed before (FP) and after cooking (CP). FP presented moisture and water activity lower than $35 \%$ and 0.95 , respectively. The $\mathrm{L}^{*}$ and $\mathrm{b}^{*}$ colour parameters were similar for pasta produced with RWF and SWF, with the major differences for pastas produce with high content of MF. Thus, with increasing of MF, pastas were redder, darker and less yellow. The CP showed high colour similarities between them. Generally, the introduction of MF changes the texture of pastas. Internal and external firmness, and adhesiveness, decreased with increasing MF and for higher drying temperatures. $\mathrm{CP}$ presented similar tendencies, with low firmness, high adhesiveness and high stickiness. The soluble solids were determined in $\mathrm{CP}$ cooking water, and range between 5.8 and $9.0 \%$, without a consistent pattern, allowing classifying the pastas as high and medium quality. Sensory analysis revealed that consumers preferred pastas produced with high content of MF with similar profiles for all the parameters tested, and the influence of the type of wheat flour was not important. It could be concluded that mushroom powder could be used to produce pastas with an improved quality and similar characteristics to regular pastas.
\end{abstract}

Keywords: shiitake, flour, noodle, physicochemical properties, sensory analysis.

\section{Introduction}

Pasta is a cereal-based food product and its importance is related with low cost, easy preparation, appreciated sensorial properties, long shelf life, playing an important role in human nutrition and culture (Bergman et al., 1994; Fu, 2008). Pasta is usually made with semolina from durum wheat and water (Marti, Pagani, 2013), but other ingredients can be added, like eggs, whey and herbal products (Nouviaire et al., 2008; Schoenlechner et al., 2010; Krishnan, Prabhasankar, 2012), which are becoming very important in the modern pasta manufacture.

The overall quality of pasta is related to its cooking properties, nutritional value, and textural characteristics (Lu et al., 2006). The high cooking quality is related to low cooking losses and minimal increase in volume during cooking ( $\mathrm{Lu}$ et al., 2016). The nutritional and textural properties of pasta are important to the acceptability by the consumers (Sobota et al., 2015; Ficco et al., 2016).

Several studies were done in order to improve the nutritional value and functional properties of pasta by substituting the semolina flour by other raw materials, such us fibres, inulin, and other materials (Tudorică et al., 2002). This replacement lead to an increase in availability of gluten-free products, and a decrease in the demand of durum wheat flour, which production is very limited leading to a partial or complete replacement of semolina with common wheat flours or other flours (Mastromatteo et al., 2011; Kim et al., 2016; Biernacka et al., 2017). However, the replacement of semolina is still a challenge, since the addition of other ingredients affects pasta properties (Lorusso et al., 2017).

Shiitake (Lentinula edobes) mushrooms are the second most produced mushrooms in the world (about 25\%) (Jiang et al., 2015). These mushrooms have a wide range of health benefits, like antiviral, antioxidative, antitumor and hypocholesterolaemic effects (Kim et al., 2014). They also present high nutritional value, having some bioactive components, like dietary fibre, antioxidants, minerals, folates, essential amino acids (such us lysine) as well as vitamins $\mathrm{B}_{1}, \mathrm{~B}_{2}, \mathrm{~B}_{3}$ (niacin) and $\mathrm{C}$ (Li et al. 2014; Jiang et al., 2015).

Mushrooms are quite perishable and deteriorate very quickly after harvesting due to their high moisture content (87-95\%) (Walde et al., 2006). Drying processes are usually used to remove water from mushrooms in order to avoid the growth of spoilage microorganisms, and biochemical reactions, such as enzymatic activity (Krokida et al., 2003). Furthermore, when there is an overproduction of mushrooms or they present commercial defects to be consumed in fresh but with quality to be used in food processing, they could be dried to produce flour for human consumption. Dried Shiitake mushrooms present an intense flavour, similar to meat or cheese, when compared with fresh mushrooms due to the breakdown of proteins into amino acids during the drying process (Qi et al., 2014), and due to lenthionine and guanosine 5'-monophosphate (5'- GMP) (Baek et al., 1989). Shiitake mushrooms could be added to food directly fresh or dehydrated, whole or in pieces or as powder, enlarging their consumption and providing beneficial health effects through food products (Lin et al., 2008).

Moreover, the introduction of mushroom powders or flours, and some derivative products from them, in pastas had been studied by several authors (Kaur et al., 2013; Kim et al., 2016; Lu et al. 2016).

In this study, Shiitake mushroom flour was added, at different proportions $(5,10$ and $15 \%)$ to regular wheat flour (RWF) and 30\% semolina wheat flour (SWF) with the aim of replacing wheat flour by mushroom flour in pasta production, with acceptable quality, in order to valorise this mushroom, creating economic benefits for producers and avoid unnecessary wastes. 


\section{Materials and Methods}

Shiitake mushrooms (Lentinula edodes) were provided by the company Ementa Saudável (Viseu, Portugal). Mushrooms were cleaned and sliced, before being dried in an FD 115 Binder ventilated drying chamber (with an air flow of $300 \mathrm{~m}^{3} \mathrm{~h}^{-1}$ ) at $40^{\circ} \mathrm{C}$, during approximately 10 hours and 30 minutes (until constant weight). After drying, shiitake mushroom slices were milled in a SK 100 Cross Beater Retsch (Kiwa International, Germany) knife with a $1 \mathrm{~mm}$ sieve to obtain the mushroom flour (MF). The powder or flour was put in a sealed bag and stored at refrigeration temperature until used.

For the preparation of the pastas two types of wheat flour were used: regular wheat flour (RWF), type 65, and wheat flour with $30 \%$ semolina (SWF) (from durum wheat). It was also tested the proportion of mushroom powder: 5, 10 and $15 \%$. Control pastas with the RWF and SWF (without mushroom flour) were produced. Tap water was added in a percentage of $30 \%$. All the ingredients were hand mixed and passed through a pasta machine Urban Living (Unclepodger enterprise, Belgium) equipped with sheet roller and sheet cutter section, in order to obtain the definitive form of pastas (Figure 1). The final pastas samples look like tagliatella, with a thickness of $0.2 \mathrm{~cm}$, width of $1 \mathrm{~cm}$ and length of $18 \mathrm{~cm}$. Pastas were used for analysis immediately after preparation.

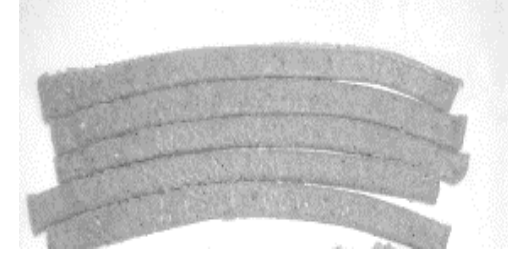

Figure 1. Example of a mushroom pasta produced

The cooking analysis of fresh pastas included cooking time and cooking loss. Optimum cooking time (the time necessary to obtain total starch gelatinization, corresponding to the disappearance of the white core) was determined following by the method 16-50 of AACC (2000). Fresh pasta (50 g) was cooked in 500 $\mathrm{mL}$ of boiling water and at every $30 \mathrm{~s}$ it was scooped out of water and squeezed between 2 pieces of glass.

Therefore, the cooking time of fresh pastas $(50 \mathrm{~g})$ cooked in $500 \mathrm{~mL}$ boiled tap water was 5 minutes for all cases. Despite this result, some authors found that the supplementation of mushroom powder significantly increase the minimum cooking time of pasta as compare to control (semolina pasta without addition of Agaricus bisporus mushroom flour) (Kaur et al., 2013). Cooking loss (expressed as percentage) was evaluated by determining the amount of solids lost in the cooking water (Curiel, et al., 2014). Cooking water collected from each sample was subjected to evaporation until constant weight at $105^{\circ} \mathrm{C}$ in an air oven FD 115 Binder (Binder, Germany) to determine the solids.

Colour was evaluated by a colorimeter CR-400 (Konica Minolta, Japan) in the CIE LAB colour space: $\mathrm{L}^{*}$ (whiteness / darkness), a* (redness / greenness), $\mathrm{b}^{*}$ (yellowness/ blueness). Ten measurements were performed on each produced pastas.

Texture was evaluated by texture profile analysis (TPA) with a texture analyser TA.XT Plus (Stable Micro Systems, United Kingdom), using a cut test with a Warner-Bratzler probe. The experimental graphs allowed estimating external firmness, inner firmness, adhesiveness and stickiness, as shown in Figure 2. The cut distance was $40 \mathrm{~mm}$, the activation force was 0.2 $\mathrm{N}$, and the test velocity was $2 \mathrm{~mm} \mathrm{~s}^{-1}$. Ten measurements for each pasta were performed.

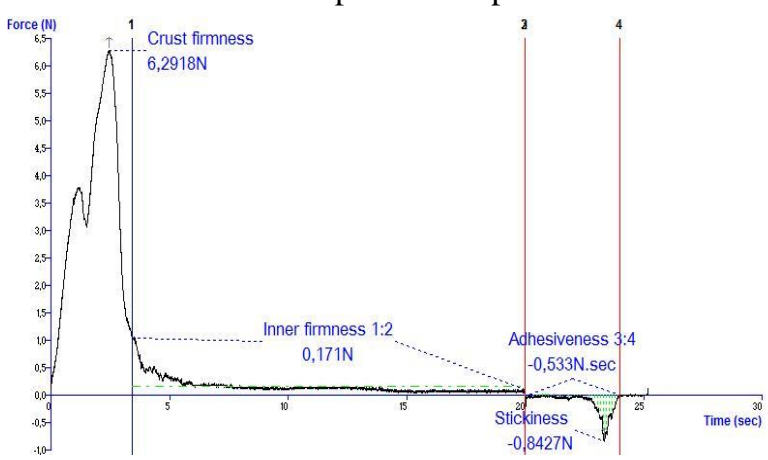

Figure 2. Example of a TPA texture profile performed to a pasta

The moisture content of pastas was determined by oven drying (AOAC, 2012). Water activity was determined by a hygrometer (Rotronic) and five determinations were made

For the sensory evaluation a sensory panel of 25 non trained assessors were used, for evaluation as a consumer panel. Although the assessors were not trained for this type of product, they were experienced in making sensory analysis. For the assessment of the sensory profile the following attributes were analysed on a 10 point scale varying from 1 (least intense) to 10 (most intense): homogeneity, proportion of smudge, colour, mushroom aroma, mushroom taste, firmness and general appreciation.

All the determinations were performed at least in triplicated for each mushroom pasta. All the results were express in mean \pm standard deviation, which was used to quantify the amount of variation or dispersion of data values.

\section{Results and Discussion}

\section{Cooking loss}

Cooking quality is related with the ability of pasta to maintain the textural properties at the optimum cooking time (Del Nobile et al., 2005). The high cooking quality of pastas is related to low cooking losses (Lu et al., 2016). Aravind et al. (2013) stated that cooking loss correlated with cooking pasta quality and explained the capacity of gluten-starch matrix to maintain the physical integrity of pasta during cooking. The percentages of soluble solids in the cooking water of pastas are showed in Table 1. The high values of soluble solids are presented by pastas produced with SWF, and the SWF pasta produced with $15 \%$ of MF has the highest amount of soluble solids (8.6\%). The 
RWF pasta with $15 \%$ MF shows the lower value of soluble solids $(5.8 \%)$. The solids loss in cooking water should not exceed 9\% (AACC, 2000), thus the values obtained in this work were within that limit. Similar results were found by Kaur et al. (2013) and Lu et al. (2016) for semolina pastas enriched with mushroom powder. The addition of mushroom flour seems to enhance the solids loss in cooking water in more obvious way in SWF, which is not the case for common wheat flour pastas. The results for SWF pastas are in accordance with those found by Kaur et al. (2013).

Table 1

Soluble solids in the water of cooked pasta

\begin{tabular}{lcc}
\hline \% MF & RWF, \% & SWF, \% \\
\hline 0 (Control) & $6.8 \pm 0.4$ & $7.1 \pm 0.5$ \\
5 & $6.1 \pm 0.3$ & $7.8 \pm 0.6$ \\
10 & $6.7 \pm 0.5$ & $7.8 \pm 0.4$ \\
15 & $5.8 \pm 0.4$ & $8.6 \pm 0.9$ \\
\hline
\end{tabular}

The encountered results could be explained by the protein content and quality, and also by the formation of a continuous protein network in entrapping starch (Pagani et al., 1996). Kim et al. (2016) mention that the increasing of cooking loss values could be attributed to a dilution of gluten matrix and protein-starch matrix due to $\beta$-glucan substitution. Thus, this disturbs result in a discontinuous network, leading to a leak solid material into the cooking water (Resmini, Pagani, 1983).

\section{Colour}

Food colour is an important characteristic considering food quality. Pasta colour results from the properties of flour or semolina but also from other raw materials used (Biernacka et al., 2017).

The results showed that the $\mathrm{L}^{*}$ values decrease with the increasing of MF content, and this is observed both for fresh and cooked pastas, probably due to the colour of shiitake flour, which is dark. It was also noticed that pastas became darker with cooking. Moreover, the SWF pastas presented a lighter intensity of colour when compared with RWF pastas, however after cooking there is no noteworthy difference.

The $a^{*}$ coordinate showed quite different values in fresh pastas, with high values for pastas produced with RWF and with high content of mushroom flour, meaning that RWF pastas are reddish brown, and this is intensified by the addition of mushroom powder. It is also possible to notice that SWF pastas presented similar tendencies as RWF pastas. Moreover, cooking causes a change in $\mathrm{a}^{*}$ values, leading to a reduction. Generally, the $a^{*}$ values are quite similar for the wheat flours used, and the main differences are in the pastas with MF. The a* value increases with the increasing of $\mathrm{MF}$, mainly when the proportion is equal or higher than $10 \%$.
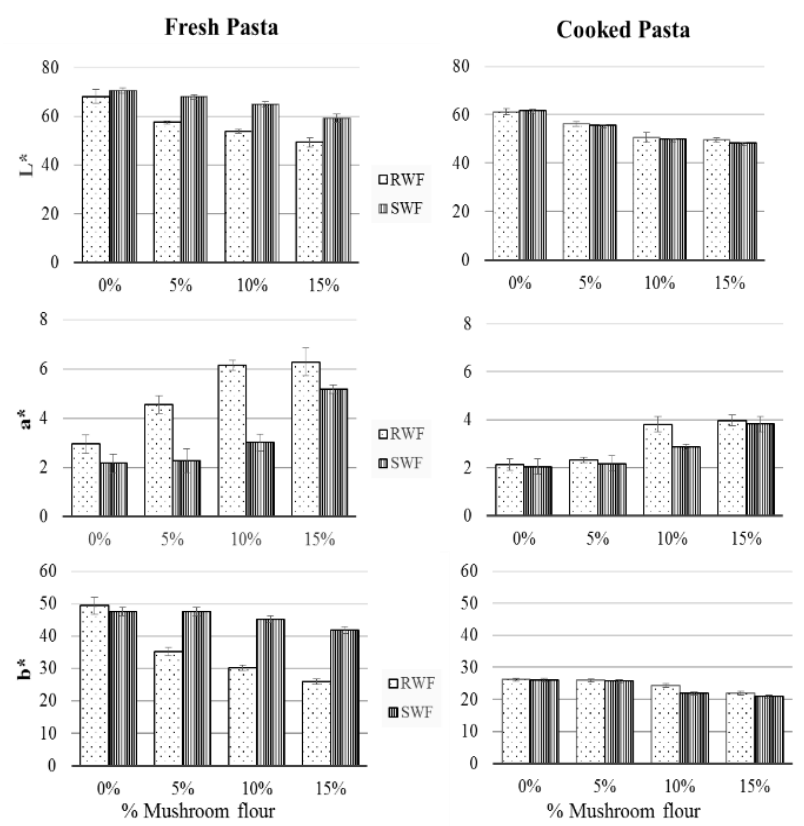

Figure 3. Colour characteristics of mushroom pastas

Kim et al. (2016) also found similar results for common wheat pastas with Pleurotus eryngii mushroom $\beta$-glucan.

Figure 3 also showed that the $b^{*}$ colour coordinate presented high values, meaning that yellow is the predominant colour. The $b^{*}$ decreased with the increasing of MF, and the SWF pastas presented high values. This means that pastas produced with SWF are more yellow and when the proportion of MF increases they became less yellow. After cooking, the $b^{*}$ values are quite similar for all pastas produced, with a slight decrease when the MF proportion increases.

In general, the CIELAB colour coordinates presented higher values for fresh pastas, which could be due to the lixiviation of colour compounds to the cooking water, what was effectively observed.

\section{Texture}

The textural characteristics of pasta are determinant in the final acceptance by consumers, and could be affected by several factors, such as type and rate of fibre and proteins included into the pasta (Tudorică et al., 2002). The textural properties of fresh and cooked pastas are presented in Tables 2 and 3, respectively. According to the results, the inner and external firmness in fresh RWF and SWF are very similar, but with pasta cooking the SWF presented lower values. Moreover, the inner and external firmness of fresh pastas decrease with the increasing of MF proportion for all the pastas, being the lowest values found for the pastas produced with $15 \% \mathrm{MF}$. Thus, pastas with MF were less firm, especially in SWF pastas. 
Table 2

Textural properties of fresh pasta

\begin{tabular}{|c|c|c|c|}
\hline Property & $\% \mathrm{MF}$ & RWF & SWF \\
\hline \multicolumn{4}{|c|}{ Inner firmness, $\mathrm{N}$} \\
\hline & 0 (Control) & $2.63 \pm 1.41$ & $2.26 \pm 0.68$ \\
\hline & 5 & $2.33 \pm 0.55$ & $1.60 \pm 0.14$ \\
\hline & 10 & $1.93 \pm 1.52$ & $0.72 \pm 0.12$ \\
\hline & 15 & $1.88 \pm 0.78$ & $0.64 \pm 0.12$ \\
\hline \multicolumn{4}{|c|}{ External firmness, $\mathrm{N}$} \\
\hline & 0 (Control) & $6.81 \pm 1.87$ & $6.01 \pm 1.44$ \\
\hline & 5 & $4.65 \pm 0.55$ & $2.31 \pm 0.36$ \\
\hline & 10 & $4.15 \pm 1.54$ & $1.57 \pm 0.26$ \\
\hline & 15 & $4.01 \pm 0.80$ & $0.86 \pm 0.19$ \\
\hline \multicolumn{4}{|c|}{ Adhesiveness, N.s } \\
\hline & 0 (Control) & $-11.12 \pm 2.29$ & $-8.15 \pm 1.69$ \\
\hline & 5 & $-7.13 \pm 1.01$ & $-3.76 \pm 1.01$ \\
\hline & 10 & $-5.30 \pm 0.77$ & $-2.62 \pm 0.09$ \\
\hline & 15 & $-3.73 \pm 0.33$ & $-2.48 \pm 0.23$ \\
\hline \multicolumn{4}{|c|}{ Stickiness, N } \\
\hline & 0 (Control) & $-10.79 \pm 2.39$ & $-6.07 \pm 2.44$ \\
\hline & 5 & $-3.45 \pm 0.45$ & $-1.71 \pm 0.19$ \\
\hline & 10 & $-2.24 \pm 0.44$ & $-1.56 \pm 0.15$ \\
\hline & 15 & $-1.13 \pm 0.25$ & $-1.43 \pm 0.26$ \\
\hline
\end{tabular}

The pasta adhesiveness and the stickiness decrease with the addition of MF, with lower values for pastas produced with SWF.

Cooked pastas showed higher values for firmness parameters when compared with fresh pastas, and these textural characteristics also decreased with the increasing of MF, but SWF pastas presented lower values of firmness parameters (Table 3). Generally, the adhesiveness and the stickiness showed low values in cooked pastas. The results also allow to say that all the pastas have similar values, considering the same textural property.

Table 3

Textural properties of cooked pasta

\begin{tabular}{|c|c|c|c|}
\hline Property & $\% \mathrm{MF}$ & RWF & SWF \\
\hline \multicolumn{4}{|c|}{ Inner firmness, $\mathrm{N}$} \\
\hline & 0 (Control) & $10.82 \pm 0.27$ & $5.21 \pm 1.13$ \\
\hline & 5 & $3.87 \pm 0.71$ & $1.93 \pm 0.36$ \\
\hline & 10 & $2.12 \pm 0.56$ & $1.67 \pm 0.26$ \\
\hline & 15 & $1.93 \pm 0.57$ & $1.26 \pm 0.20$ \\
\hline \multicolumn{4}{|c|}{ External firmness, $\mathrm{N}$} \\
\hline & 0 (Control) & $13.22 \pm 2.18$ & $9.06 \pm 1.44$ \\
\hline & 5 & $8.24 \pm 0.91$ & $5.60 \pm 0.57$ \\
\hline & 10 & $5.80 \pm 0.94$ & $5.16 \pm 0.12$ \\
\hline & 15 & $4.86 \pm 1.06$ & $4.65 \pm 0.18$ \\
\hline \multicolumn{4}{|c|}{ Adhesiveness, N.s } \\
\hline & 0 (Control) & $-2.88 \pm 0.48$ & $-3.23 \pm 1.17$ \\
\hline & 5 & $-3.01 \pm 0.83$ & $-3.01 \pm 0.79$ \\
\hline & 10 & $-2.58 \pm 0.88$ & $-2.37 \pm 0.28$ \\
\hline & 15 & $-2.37 \pm 1.01$ & $-1.77 \pm 0.35$ \\
\hline \multicolumn{4}{|c|}{ Stickiness, N } \\
\hline & 0 (Control) & $-1,51 \pm 0.88$ & $-1.65 \pm 0.18$ \\
\hline & 5 & $-1.71 \pm 0.26$ & $-1.71 \pm 0.30$ \\
\hline & 10 & $-1.63 \pm 0.31$ & $-1.38 \pm 0.13$ \\
\hline & 15 & $-1.60 \pm 0.27$ & $-1.46 \pm 0.19$ \\
\hline
\end{tabular}

The encountered results could be explained by the physical competition between protein interaction and coagulation in a continuous network and starch (Lu et al., 2016). Moreover, the firmness is one of the most important evaluation indexes of pasta, which measures the force required for shearing the pasta. The reduction of pasta firmness could be also associated with the role of fibre from mushroom powder in disrupting the protein-starch matrix of pasta (Tudorică et al., 2002).

\section{Moisture and water activity}

The moisture and water activity $\left(\mathrm{a}_{\mathrm{w}}\right)$ are important factors for food storage. Thus, these parameters were also determined for both fresh and cooked pastes to estimate if there were considerable differences between them. The results of these determinations were determined just for RWF pastas (Figure 4). In fact, considering the above results, it is possible to notice that in a general overview, the pastas with better characteristics were the ones produced with RWF.

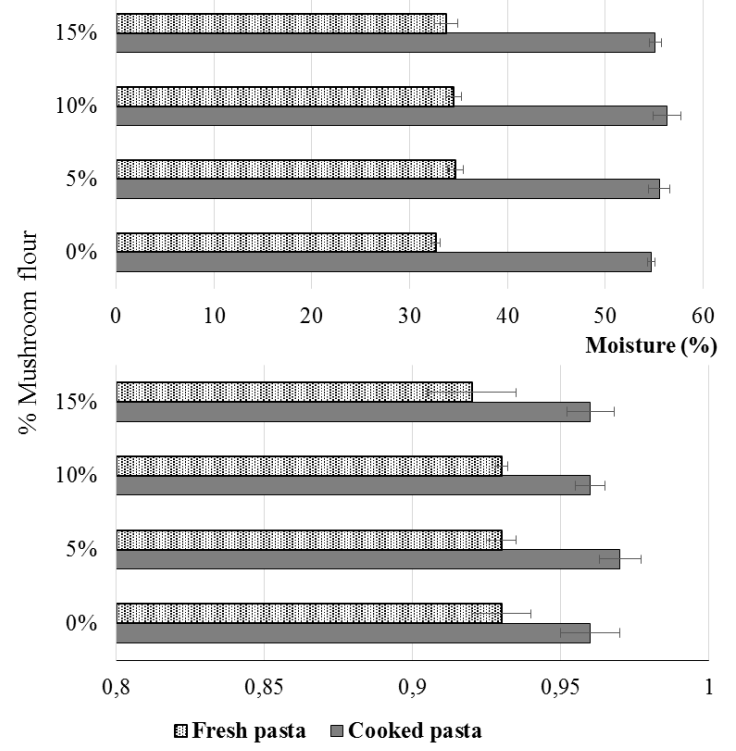

Figure 4. Moisture and water activity $\left(a_{w}\right)$ of RWF mushroom pastas

Generally, the moisture content and $\mathrm{a}_{\mathrm{w}}$ of all pastas were similar for pastas produced with the same wheat flour, and the cooked pastas presented higher values, as expected, about $30 \%$ more. Krugel at al. (1996) mention the limit of $35 \%$ of moisture content for fresh pasta, being this fulfilled for all analysed pastas. Furthermore, pastas presented also similar $\mathrm{a}_{\mathrm{w}}$ between them, for fresh pastas varying between $0.92-0.93$ and for cooked pastas between 0.96-0.97. Regarding these results, it is possible to state that the water present in all pastas is available to react with other components of the pasta matrix and also the fungi development is a possible concern. According to Neto et al. (2005), most of the microorganisms grow in the range 0.90 to 0.99 (medium and high values of aw), and hence the studied pastas may be susceptible to the growth of microorganisms.

\section{Sensorial evaluation}

The sensorial profiles for both wheat cooked pastas, RWF and SWF, and with addition of mushroom powder are shown in Figure 5. 

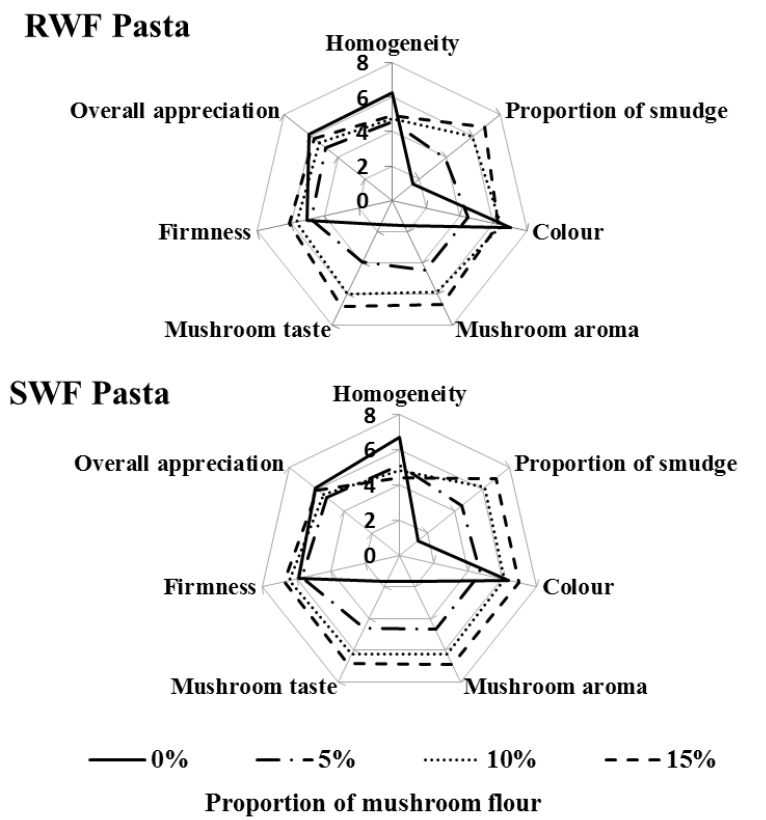

\section{Figure 5. Sensory profiles of RWF and SWF cooked pastas}

The profiles of mushroom pastas are quite different from the control pasta, without addition of MF. However, the assessors had a similar sensorial appreciation for pastas with high proportion of MF, and for both wheat flours. The pasta with $5 \%$ of mushroom powder presented low scores for proportion of smudge, colour, mushroom aroma and taste when compared with the other two mushroom flours. Furthermore, the firmness and the global appreciation were similar for all the pastas. The $15 \%$ mushroom flour pastas were the most appreciate ones, presenting high scores for all the sensorial attributes evaluated.

\section{Conclusions}

The results of this study revealed that regular wheat flour type 65 with shiitake powder shows potential as an alternative to flour with $30 \%$ of semolina for pasta production. The addition of mushroom flour had a little effect on the cooking time of pastas, but it had a pronounced effect on cooking loss in semolina wheat flour pastas. The mushroom flour also strongly influenced the colour, especially causing a decrease in the lightness and an increase in redness of the obtained products. With cooking procedure the colour and texture of regular wheat flour and semolina pastas were less discrepant, meaning that they did not present marked differences. Moreover, the addition of mushroom flour decreased the firmness, the adhesiveness and stickiness of fresh pastas. With cooking, the pastas became more firm, with less adhesiveness and stickiness when compared with the respective fresh pastas. This means that cooking can improve the textural properties of pastas. The assessors also attributed similar scores to pastas with high content of MF, being the $15 \%$ MF pastas the most appreciated.

Therefore, the results showed that addition of $15 \%$ mushroom powder was considered as optimum amount to make pasta with regular wheat flour, with good acceptable sensorial scores, and also with health and economic benefits. On this last account, the addition of mushroom flour could possible substitute semolina pasta, which is more expensive, and on the other hand it is possible to avoid waste of shiitake mushrooms and the producer could also leak all the product, enhancing the profits.

\section{Acknowledgment}

This work is financed by national funds through FCT Fundação para a Ciência e Tecnologia, I.P., under the project UID/Multi/04016/2016.

Furthermore we would like to thank the Instituto Politécnico de Viseu and CI\&DETS for their support, and also to the company Ementa Saudável (Viseu, Portugal) for Shiitake mushroom supply.

\section{References}

1. AACC (2000). Approved methods of the American Association of Cereal Chemists. St. Paul., Minnesota, USA. American Association of Cereal Chemistry Inc.

2. AOAC. (2012). Official Methods of Analysis of AOAC International (19th Edition). Arligton, VA: Association of Official Analytical Chemists.

3. Aravind N., Sissons M., Fellows C. M., Blazek J., Gilbert E. P. (2013) Optimisation of resistant starch II and III levels in durum wheat pasta to reduce in vitro digestibility while maintaining processing and sensorial characteristics. Food Chemistry, Vol. 136, p. 1100-1109.

4. Baek H. H, Kim D. M, Kim K. H. (1989) Changes in quality of shiitake mushroom (Lentinus edodes). Korean Journal of Food Science and Technology, Vol. 21, p. 145-148.

5. Bergman C. J., Gualberto D. G., Weber C. W. (1994) Development of a high-temperature-dried soft wheat pasta supplemented with cowpea (Vigna unguiculata (L.) Walp.). Cooking quality, color, and sensory evaluation. Cereal Chemistry, Vol. 71, p. 523-27.

6. Biernacka B., DzikI D., Gawlik-Dziki U., Rózylo R. (2017) Physical, sensorial, and antioxidant properties of common wheat pasta enriched with carob fiber. $L W T-$ Food Science and Technology, Vol. 77, p. 186-192.

7. Curiel J. A., Coda R., Limitone A., Katina K., Raulio M., Giuliani G., Rizzello C. G., Gobbetti M. (2014) Manufactured and characterization of pasta made with wheat flour rendered gluten-free using fungal proteases and selected sourdough lactic acid bacteria. Journal of Cereal Science, Vol. 59, p. 79-87.

8. D`Amico S., Mäschale J., Jekle M., Tömösközi S., Langó B., Schoenlechner R. (2015) Effect of high temperature drying on gluten-free pasta properties. LWT - Food Science and Technology, Vol. 63, p. 391-399.

9. Del Nobile M. A., Baiano A., Conte A., Mocci G. (2005) Influence of protein content on spaghetti cooking quality. Journal of Cereal Science, Vol. 41, p. 347-356.

10. Fu B. X. (2008) Asian noodles: history, classification, raw materials, and processing. Food Research International, Vol. 41, p. 888-902. 
11. Jiang T., Luo Z., Ying T. (2015) Fumigation with essential oils improves sensory quality and enhanced antioxidant ability of shiitake mushroom (Lentinus edodes). Food Chemistry, Vol. 172, p. 692-698.

12. Kaur G., Sharma S., Nagi H. P. S. (2013) Enrichment of pasta with differential past proteins. Journal of Food Science and Technology, Vol. 50, p. 1000-1005.

13. Kim M. J., Lee J., Lee J. S. (2014) Effect of ultraviolet-B irradiation on antioxidative properties of aqueous extracts from shiitake (Lentinus edodes) mushrooms. International Journal of Food Science and Technology, Vol. 49, p. 2276-2282.

14. Krishnan M., Prabhasankar P. (2012) Health-based pasta: redefining the concept of the next generation convenience food. Critical review in Food Science and Nutrition, Vol. 52, p. 9-20.

15. Li Y., Ishikawa Y., Satake T., Kitazawa H., Qiu X., Rung-Chang S. (2014) Effect of active modified atmosphere packaging with different initial gas compositions on nutritional compounds of shiitake mushrooms (Lentinus edodes). Postharvest Biology and Technology, Vol. 92, p. 107-113.

16. Lin L.-Y., Tseng Y.-H, Li R-C, Mau J.-L. (2008) Quality of shiitake stipe bread. Journal of Food Processing and Preservation, Vol. 32, p. 1002-1015.

17. Lorusso A., Verni M., Montemurro M., Coda R., Gobbetti M., Rizzello C. G. (2017) Use of fermented quinoa flour for paste making and evaluation of the technological and nutritional features. LWT - Food Science and Technology, Vol. 78, p. 215-221.

18. Lu X., Brennan M. A., Serventi L., Mason S., Brennan C. S. (2016) How the inclusion of mushroom powder can affect the physicochemical characteristics of pasta.
International Journal of Food Science and Technology, Vol. 51, p. 2433-2439.

19. Marti A., Pagani M. A. (2013) What can play the role of gluten in gluten free pasta? Trends in Food Science and Technology, Vol. 31, p. 63-71.

20. Mastromatteo M., Chillo S, Iannetti M., Civica V., Del Nobile M. A. (2011) Formulation optimization of glutenfree functional spaghetti based on quinoa, maize and soy flours. International Journal of Food Science and Technology, Vol. 46, p. 1201-1208.

21. Neto C. J. F., Figueiredo R. M. F., M.Queiroz A. J. (2005) Sensory evaluation and water activity of the seasoned cassava flour. Lavras, Vol. 29, p. 795-802.

22. Nouviaire A., Lancien R., Maache-Rezzoug Z. (2008) Influence of hydrothermal treatment on rheological and cooking characteristics of fresh egg pasta. Journal of Cereal Science, Vol. 47, p. 283-291.

23. Qi L. L., Zhang M., Mujumdar A. S., Meng X. Y., Chen H. Z. (2014) Comparison of drying characteristics and quality of shiitake mushrooms (Lentinus edodes) using different drying methods. Drying Technology, Vol. 32, p. 1751-1761.

24. Resmini P., Pagani M. A. (1983) Ultrastructure studies of pasta- a review. Food Microstructure, Vol. 2, p. 1-12.

25. Schoenlechner R., Drausinger J., Ottenschlaeger V., Jurackova K., Berghofer E. (2010) Functional properties of gluten-free pasta produced from amaranth, quinoa and buckwheat. Plant Foods for Human Nutrition, Vol. 65, p. 339-349.

26. Tudorică C. M., Kuri V., Brennan C. S. (2002). Nutritional and physicochemical characteristics of dietary fiber enriched pasta. Journal of Agricultural and Food Chemistry, Vol. 50, p. 347-356. 